\title{
Photoinduced Fluorescence Patterning with a $t$-Boc Protected Dihydroxyphenylene Derivative
}

\author{
Sumi Lee, Tae-Young Ahn, ${ }^{\dagger}$ Sangjun Kim, Young-Sik Jung, ${ }^{\dagger, *}$ and Jong-Man Kim* \\ Department of Chemical Engineering, Hanyang University, Seoul 133-791, Korea. *E-mail: jmk@hanyang.ac.kr \\ ${ }^{\dagger}$ Drug Discovery Division, Korea Research Institute of Chemical Technology, Daejeon 305-606, Korea \\ *E-mail: ysjung@krict.re.kr \\ Received August 9, 2010, Accepted August 19, 2010
}

Key Words: Fluorescence patterning, Spin-coated film, Photo acid generator (PAG)

Generation of patterned functional images on solid substrates has attracted much attention owing to their potential technological applications. For instance, patterned fluorescent images could be utilized in many areas like displays, optical memory devices, molecular switches, sensors, and imaging industries. ${ }^{1-7}$ In general, fluorescence patterning on a solid substrate has so far been achieved by employing a so called 'two-step procedure', which involves the formation of reactive species such as amine, carboxylic acid, and hydroxyl groups in the first photochemical step. The reactive species in the exposed area then interact with fluorescent dyes (wet processing) in the second step.

In order to avoid the intrinsic problems (eg. requirement of wet developing step) associated with the 'two-step procedure', we have developed a new method called 'precursor approach' for the fabrication of patterned fluorescence images. ${ }^{8}$ The concept of the 'precursor approach' is based on a fluorescence change by photoinduced structural transformations of precursor molecules. For example, a dye molecule is nonfluorescent (or displays a single fluorescent color) when the key functional group of the dye molecule is protected with a protecting group. If the protecting group is removed under photoinduced chemical transformation, the fluorescence can be regenerated (or a different fluorescence color is emitted), allowing patterned fluorescent images by selective removal of the protecting group in the exposed areas. The 'precursor approach' thus allows efficient generation of patterned functional images in one step without the need for additional wet developing processes.

Among the various protecting groups employed in the precursor molecules, tert-butyloxycarbonyl ( $t$-Boc) group is unique since $t$-Boc protecting group can be readily introduced to an amine or hydroxyl group and it can be selectively removed by photogenerated acid. ${ }^{9} \mathrm{We}$ have previously reported patterned fluorescence images with $t$-Boc protected precursor molecules. ${ }^{10}$ In this communication, we report a new precursor molecule, (2E,2'E)-diethyl 3,3'-(2,5-bis(tert-butoxycarbonyloxy)-1,4phenylene)diacrylate ( $\boldsymbol{t}$-Boc-DDPD) for efficient fluorescence patterning in polymer film.

Scheme 1 shows reaction conditions employed for the preparation of the precursor molecule $\boldsymbol{t}$-Boc-DDPD. Treatment of 1,4-dimethoxybenzene (1) with formaldehyde in acidic condition produced 1,4-bis(chloromethyl)-2,5-dimethoxybenzene (2). The bischloromethylated compound 2 was converted to 2,5-dimethoxyterephthaldehyde (3) in high yield. Removal of the methyl group in the terephthalaldehyde $\mathbf{3}$ was carried out
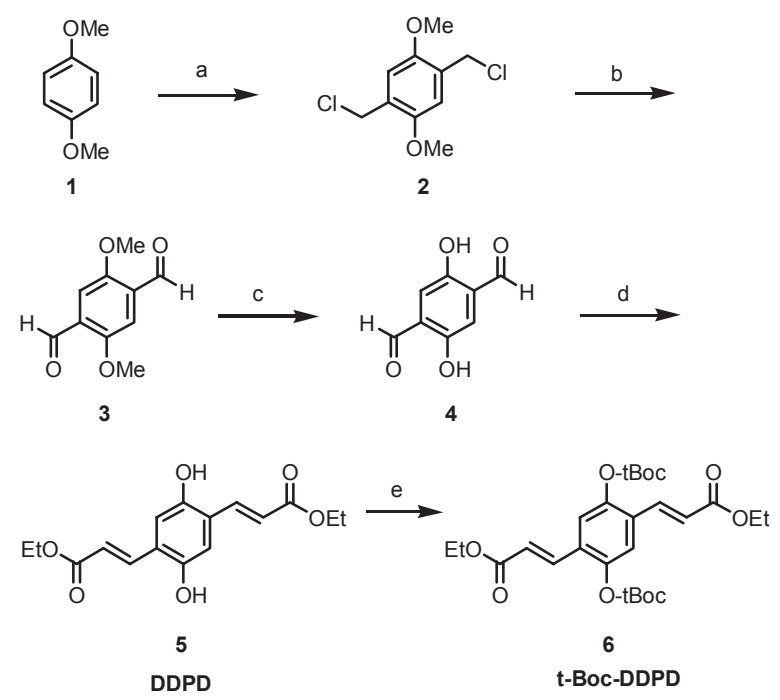

Scheme 1. Synthesis of $\boldsymbol{t}$-Boc-DDPD. a) formaldehyde, $\mathrm{HCl}$, dioxane, $25^{\circ} \mathrm{C}, 3 \mathrm{~h}, 56 \%$, b) i: HMTA, $\mathrm{CHCl}_{3}$, reflux, $16 \mathrm{~h}$, ii: formaldehyde, $\mathrm{H}_{2} \mathrm{O}$, reflux, $21 \mathrm{~h}, 82 \%$, c) $\mathrm{BBr}_{3}, \mathrm{CH}_{2} \mathrm{Cl}_{2}, 25^{\circ} \mathrm{C}, 3 \mathrm{~h}, 58 \%$, d) $\mathrm{Ph}_{3} \mathrm{PCH}_{2} \mathrm{C}$ (=O)OEt, benzene, $70{ }^{\circ} \mathrm{C}, 12 \mathrm{~h}, 85 \%$, e) di-tert-butyl dicarbonate, pyridine, $25^{\circ} \mathrm{C}, 6 \mathrm{~h}, 91 \%$

with $\mathrm{BBr}_{3}$ to yield 2,5-dihydroxyterephthaldehyde (4). ${ }^{11}$ Treatment of $\mathbf{4}$ with ethyl(triphenylphosphoranylidene) acetate under a Wittig reaction condition gave ( $\left.2 E, 2^{\prime} E\right)$-diethyl 3,3-(2,5-dihydroxy-1,4-phenylene)diacrylate (DDPD) (5). ${ }^{12}$ Reaction of DDPD with di-tert-butyl dicarbonate in pyridine allowed efficient formation of the desired precursor molecule $\boldsymbol{t}$-BocDDPD. ${ }^{13}$

We next investigated the fluorescence emission of the unprotected DDPD and the $t$-Boc protected precursor molecule $\boldsymbol{t}$-Boc-DDPD. As shown in Figure 1, a strong fluorescence emission is observed with the unprotected DDPD with an emission maximum at $466 \mathrm{~nm}$. In contrast, the $t$-Boc protected compound $\boldsymbol{t}$-Boc-DDPD emits a relatively weak fluorescence with a significant blue shift in its emission maximum. This interesting observation gave us the motivation for this work, which was to convert $\boldsymbol{t}$-Boc-DDPD to DDPD, thereby changing its fluorescence color and intensity. Technically, the $t$-Boc protecting group in the precursor molecule is acid labile and should be readily removed by photoinduced chemical transformation.

In order to generate patterned fluorescence images in the polymer film, the 'chemical amplification' ${ }^{15}$ technique was em- 


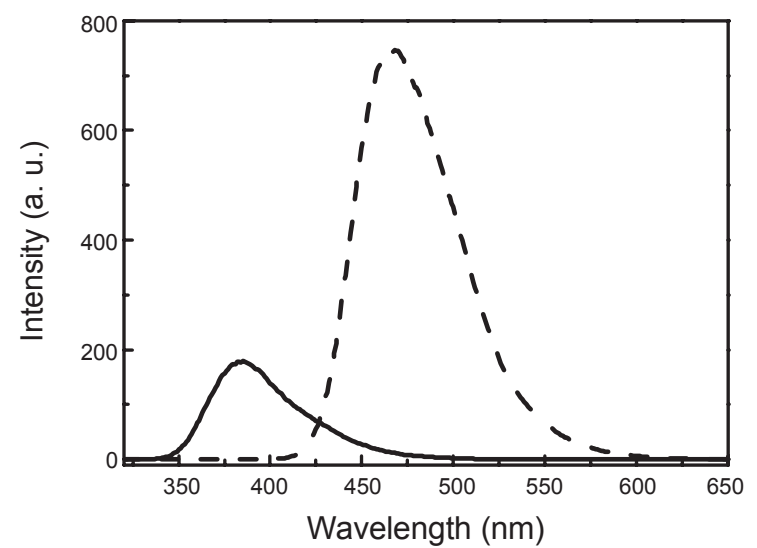

Figure 1. Fluorescence spectra of THF solution $(10 \mu \mathrm{M})$ containing DDPD (dash line) and $\boldsymbol{t}$-Boc-DDPD (solid line). Excitation at $385 \mathrm{~nm}$ for DDPD and $300 \mathrm{~nm}$ for $\boldsymbol{t}$-Boc-DDPD, respectively.

ployed. This process utilizes photoinduced generation of strong acids from a photoacid generator (PAG). The photoinduced generated acids promote the deprotection of the $t$-Boc protecting groups during post-exposure bake (PEB) of the polymer film. Since the $t$-Boc group of the $t$-Boc-DDPD is acid labile, the protecting groups can be removed by photochemically generated acid from PAG in the polymer film. If acid moieties are generated by photomasked irradiation, only the areas exposed to UV light would undergo the deprotection reaction.

In order to test the above proposal, a chloroform solution containing the $t$-Boc-protected precursor molecule $\boldsymbol{t}$-Boc-DDPD (19 wt \%), poly(methyl methacrylate) (PMMA) (80 wt \%), and triphenylsulfonium triflate ( $1 \mathrm{wt} \%)$ as a PAG was spin-coated at $3000 \mathrm{rpm}$ for $30 \mathrm{~s}$, followed by a prebaking at $120^{\circ} \mathrm{C}$ for $30 \mathrm{~s}$ on a glass substrate. The resulting thin film was exposed to UV light $\left(254 \mathrm{~nm}, 1 \mathrm{~mW} / \mathrm{cm}^{2}\right)$ for 3 min through a photomask followed by PEB at $100{ }^{\circ} \mathrm{C}$ for $1 \mathrm{~min}$. The fluorescence microscopic images of the UV and heat-treated film are displayed in Figure 2. Interestingly, three fluorescent colors - red, green and bright blue were observed exclusively from the UV-exposed areas. Excitation wavelengths for each of the images are $546 \mathrm{~nm}$ (red),

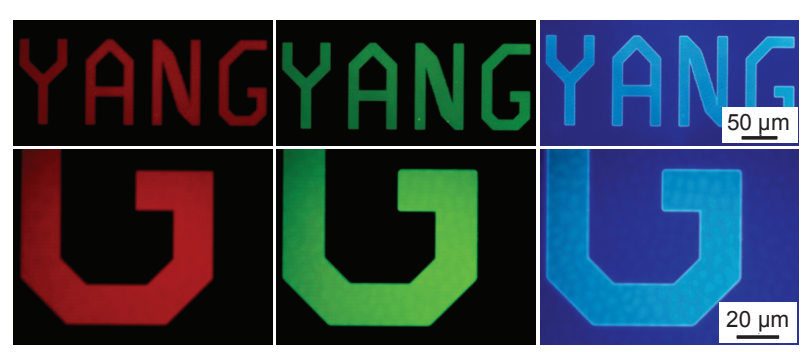

Figure 2. Patterned fluorescence images of a spin-coated film on a glass substrate containing $\boldsymbol{t}$-Boc-DDPD after photomasked irradiation with $254 \mathrm{~nm}\left(1 \mathrm{~mW} / \mathrm{cm}^{2}\right) \mathrm{UV}$ irradiation for $3 \mathrm{~min}$ and PEB $\left(100{ }^{\circ} \mathrm{C}\right.$, $1 \mathrm{~min}$ ) process. Excitation wavelength: red $(546 \mathrm{~nm})$, green $(488 \mathrm{~nm})$, and blue $(357 \mathrm{~nm})$, Exposure time: red (1/9 s), green (1/9 s), and blue $(1 / 120 s)$
$488 \mathrm{~nm}$ (green), and $357 \mathrm{~nm}$ (blue), respectively. Among the three colored patterns, the blue image was found to be the brightest and this is consistent with the fluorescence spectra shown in Figure 1. Removal of the $t$-Boc protecting group in the polymer was confirmed by UV-visible spectroscopy, observing red shift of absorption maximum after UV irradiation followed by PEB process (Figure S3).

In summary, we have developed an approach for the production of patterned fluorescence images in spin-coated polymer film. The methodology employs a $t$-Boc protected dihydroxyphenylene derivative as the precursor molecule. Photomasked irradiation of the film with UV light (254 nm) afforded clean patterned fluorescence images with red, green and blue colors.

Acknowledgments. This work was supported by Research Foundation of Korea (KRF-2007-313-D00208).

\section{References and Notes}

1. For recent review, see: Kim, J.-M. Macromol. Rapid Commun. 2007, 28, 1191.

2. Lim, S.-J.; Seo, J.; Park, S. Y. J. Am. Chem. Soc. 2006, 128, 14542.

3. Kwak, G.; Lee, W.-E.; Kim, W.-H.; Lee, H. Chem. Commun. 2009, 2112.

4. Lee, J. K.; Kim, H.-J.; Kim, T. H.; Lee, C.-H.; Park, W. H.; Kim, J.; Lee, T. S. Macromolecules 2005, 38, 9427.

5. Scaiano, J. C.; Laferriere, M.; Ivan, M. G.; Taylor, G. N. Macromolecules 2003, 36, 6692 .

6. Hahn, M. S.; Miller, J. S.; West, J. L. Adv. Mater. 2006, 18, 2679.

7. Cho, S.-Y.; Song, Y.-K.; Kim, J.-G.; Oh, S.-Y.; Chung, Chan.-M. Tetrahedron Lett. 2009, 50, 4769.

8. Kim, J.-M.; Kang, J.-H.; Han, D.-K.; Lee, C.-W.; Ahn, K.-D. Chem. Mater. 1998, 10, 2332.

9. Kim, J.-M.; Chang, T.-E.; Kang, J.-H.; Han, D. K.; Ahn, K.-D. Adv. Mater. 1999, 11, 1499.

10. Lee, C. H.; Kim, J.-M. Bull. Korean Chem. Soc. 2008, 29, 1657.

11. Ando, R.; Ono, H.; Yagyu, T.; Maeda, M. Inorg. Chim. Acta 2004, $357,817$.

12. Compound 4 has been reported in the literature. ${ }^{14}$ Ethyl(triphenylphosphoranylidene) acetate $(1.04 \mathrm{~g}, 9 \mathrm{mmol})$ and 2,5-dihydroxyterephthaldehyde (498 mg, $3 \mathrm{mmol}$ ) were dissolved in $40 \mathrm{~mL}$ of benzene. The mixture was stirred at $70{ }^{\circ} \mathrm{C}$ for $12 \mathrm{~h}$. After cooling, the reaction mixture was filtered, and the yellow solid was dried under vaccum to obtain DDPD in $85 \%$ yield. $\mathrm{mp} 264.9-265.1{ }^{\circ} \mathrm{C}$; ${ }^{1} \mathrm{H}$ NMR $\left(300 \mathrm{MHz}\right.$, in DMSO- $\left.d_{6}\right) \delta 9.81(\mathrm{~s}, 2 \mathrm{H}), 7.78(\mathrm{~d}, 2 \mathrm{H})$, 7.02 (s, 2H), 6.48 (d, 2H), 4.19 (q, 4H), $1.25(\mathrm{t}, 6 \mathrm{H}) ;{ }^{13} \mathrm{C}$ NMR $\left(75 \mathrm{MHz}\right.$, in DMSO- $\left.d_{6}\right) \delta 14.92,60.70,115.46,119.02,124.58$, $139.87,150.24,167.05$.

13. A mixture of DDPD (306 mg, $1 \mathrm{mmol})$ and di-tert-butyl dicarbonate $(545 \mathrm{mg}, 2.5 \mathrm{mmol})$ in $20 \mathrm{~mL}$ of pyridine was stirred at room temperature for $6 \mathrm{~h}$. The mixture was concentrated in vacuo. $10 \mathrm{~mL}$ of water was added to the residue and the precipitate was filtered off, washed with water, and dried. The product was obtained as a white solid in $91 \%$ yield. mp $176.3-176.4{ }^{\circ} \mathrm{C} ;{ }^{1} \mathrm{H}$ NMR (300 $\mathrm{MHz}$, in $\left.\mathrm{CDCl}_{3}\right) \delta 7.74(\mathrm{~d}, 2 \mathrm{H}), 7.44(\mathrm{~s}, 2 \mathrm{H}), 6.50(\mathrm{~d}, 2 \mathrm{H}), 4.27$ $(\mathrm{q}, 4 \mathrm{H}), 1.55(\mathrm{~s}, 18 \mathrm{H}), 1.32(\mathrm{t}, 6 \mathrm{H}),{ }^{13} \mathrm{C}$ NMR $\left(75 \mathrm{MHz}\right.$, in $\left.\mathrm{CDCl}_{3}\right)$ $\delta 14.49,27.85,60.99,84.89,121.92,122.37,130.08,136.65$, $147.26,151.38,166.45$.

14. Nicolaides, D. N.; Fylaktakidou, K. C.; Litinas, K. E.; Adamopoulos, S. G. J. Heterocyclic Chem. 1998, 35, 91.

15. Ito, H.; Wilson, C. G. Polym. Eng. Sci. 1983, 23, 1012. 